\title{
FAKTOR DETERMINAN YANG DAPAT MEMPENGARUHI KINERJA GURU PAUD (STUDI SURVEY DI KORWIL BIDANG PENDIDIKAN KECAMATAN BUNGBULANG KABUPATEN GARUT)
}

\author{
Sri Rochani Mulyani ${ }^{1}$, Didin Saepudin ${ }^{2}$, M. Gunawan ${ }^{3}$ \\ 1,2,3 Program Pascasarjana Universitas Sangga Buana \\ ${ }^{1}$ korespondensi : sri.rochani.mulyani@gmail.com
}

\begin{abstract}
This study aims to determine how the influence of transformational leadership, pedagogic competence, work motivation on the performance of Early Childhood Education (PAUD) teachers in the Regional Coordinator for Education, using the object of PAUD research in Bungbulang District, Garut Regency. The sample of this research is PAUD teachers as many as 75 respondents. The research method uses a quantitative approach, the research instrument uses a questionnaire and multiple regression analysis. The results of descriptive analysis research, respondents' opinions about transformational leadership, pedagogic competence, work motivation on PAUD teacher performance, on average are still considered good enough category, while the results of verification analysis show partially or simultaneously transformational leadership, pedagogic competence and work motivation. has a significant effect on the performance of PAUD teachers, with a correlation coefficient $(r)$ of 0.860 , there is a very strong relationship between transformational leadership, pedagogic competence, work motivation and PAUD teacher performance, while $R^{2}$ is $74 \%$, meaning that $P A U D$ teacher performance is still influenced by variables that are not used as the model of this research by 26\%. Transformational leadership must be further improved by developing teachers so that they have personality, professional and social competencies. Pedagogic competence is considered good.
\end{abstract}

Keywords : transformational leadership, pedagogic competence, motivation work on teacher performance.

\begin{abstract}
ABSTRAK
Penelitian ini bertujuan untuk mengetahui bagaimana pengaruh kepemimpinan transformasional, kompetensi pedagogik, motivasi kerja terhadap kinerja guru Pendidikan Anak Usia Dini (PAUD) di Koordinator Wilayah Pendidikan, dengan menggunakan objek penelitian PAUD di Kecamatan Bungbulang Kabupaten Garut. Sampel penelitian ini adalah guru PAUD sebanyak 75 responden. Metode penelitian menggunakan pendekatan kuantitatif, instrumen penelitian menggunakan angket dan analisis regresi berganda. Hasil penelitian analisis deskriptif, pendapat responden tentang kepemimpinan transformasional, kompetensi pedagogik, motivasi kerja terhadap kinerja guru PAUD rata-rata masih tergolong kategori cukup baik, sedangkan hasil analisis verifikasi menunjukkan secara parsial atau simultan kepemimpinan transformasional, kompetensi pedagogik dan kerja motivasi. berpengaruh signifikan terhadap kinerja guru PAUD, dengan koefisien korelasi (r) sebesar 0,860, terdapat hubungan yang sangat kuat antara kepemimpinan transformasional, kompetensi pedagogik, motivasi kerja dan kinerja guru PAUD, sedangkan R2 sebesar 74\%, artinya PAUD kinerja guru masih dipengaruhi oleh variabel yang tidak dijadikan model penelitian ini sebesar $26 \%$. Kepemimpinan transformasional harus lebih ditingkatkan dengan mengembangkan guru agar memiliki kompetensi kepribadian, profesional dan sosial. Kompetensi pedagogik dinilai baik.
\end{abstract}

Kata kunci : kepemimpinan transformasional, kompetensi pedagogik, motivasi kerja terhadap kinerja guru.

PENDAHULUAN

Undang-Undang Republik Indonesia No 20

Tahun 2003 Sistem tentang Sistem

Pendidikan Nasional Pasal 1 ayat 14 menjelaskan bahwa Pendidikan anak usia dini merupakan suatu upaya pembinaan yang ditujukan kepada anak sejak lahir sampai dengan usia enam tahun yang dilakukan 
melalui pemberian rangsangan pendidikan untuk membantu pertumbuhan dan perkembangan jasmani dan rohani anak agar memiliki kesiapan dalam memasuki pendidikan lebih lanjut. Kompetensi guru PAUD dan pendamping seperti yang dijelaskan dalam Permendiknas No 16 Tahun 2007 dan Permendiknas No 58 Tahun 2009 meliputi kompetensi pedagogik, kompetensi kepribadian, kompetensi sosial, dan kompetensi profesional. Sementara itu masih dalam Permendiknas No 58 Tahun 2009 dijelaskan pula mengenai kompetensi untuk pengasuh PAUD yaitu memahami dasar-dasar pengasuhan, terampil melaksanakan pengasuhan, dan bersikap \& berprilaku sesuai dengan kebutuhan psikologi anak.

Hasil penelitian awal menggunakan responden guru PAUD, menunjukkan kinerja guru kurang optimal, yang disebabkan karena faktor kepemimpinan transfomasional, belum mampu mendorong motivasi guru untuk meningkatkan kompetensi pedagogik, sebagai landasan utama komptensi yang harus dimiliki seorang guru. Kinerja guru dipengaruhi oleh kepemimpinan transformasional [1].

Kepemimpinan Transformasional adalah memberikan penghargaan kepada yang berprestasi dan memberikan hukuman kepada yang belum berprestasi seperti yang diharapkan, hal ini tentunya akan berdampak pada motivasi guru [1]. Peraturan Pemerintah Republik Indonesia Tahun 2005 tentang Standar Nasional Pendidikan, penjelasan Pasal 28 Ayat (3) butir (a) Kompetensi pedagogik adalah kemampuan mengelola pembelajaran peserta didik yang meliputi pemahaman terhadap peserta didik, perancangan pembelajaran, evaluasi hasil belajar, dan pengembangan peserta didik untuk mengaktualisasikan berbagai potensi yang dimilikinya. Dengan demikian menjadi satu kesatuan yang saling mempengaruhi, bahwa kepemimpinan transformasional, harus dapat mendorong guru memiliki kompetensi pedagogic dan motivasi kerja, sehingga akan mendorong kinerja guru. Penelitian ini dilakukan di PAUD Korwil Bidang Akademik Pendidikan Kecamatan Bungbulang Kabupaten Garut menggambarkan bagaimana Jumlah Satuan Pendidikan PAUD di Kabupaten Garut, meliiputi 42 Kantor Kecamatan sebanyak 2.453 Sekolah. Kecamatan Bungbulang (99 sekoah) merupakan uruta ke tiga setelah Kecamatan Karangpawitan (113 sekolah) dan Kecamatan Taroging Kidul (113 sekolah). Dengan demikian aspek manajerial dilingkungan Satuan Pendidikan PAUD Kecamatan Bungbulang, layak untuk diteliti. Disamping permasalahan yang ditemukan di lapangan cukup kompleks.

\section{TINJAUAN PUSTAKA}

Manajemen pendidikan adalah "Process of bringing men and materials together for effective and functional teaching and learning in the schools" [2]. Kepemimpinan Transformasional adalah leadership when leaders broaden and elevate followers' interests and stir followers to look beyond their own interest to the good of others [3]. 
Kepemimpinan Transformasional adalah Kepemimpinan ketika pemimpin memperluas dan meningkatkan tingkat kepentingan pengikutnya dan mengendalikan pengikutnya untuk melihat lebih atas lagi dari tingkat kepentingannya sehingga pengikut akan memperoleh kinerja yang lebih baik jika dibandingkan dengan pihak lain [3]. Kepemimpinan transformasional itu penting karena para pengikut yang dilayani oleh pemimpin yang menerapkan kepemimpinan transformasional akan menjadi lebih sehat, lebih bijak, lebih bebas, mempunyai otonom, dan lebih mungkin untuk menjadi pelayan bagi orang lain [4]. Dimensi dari Kepemimpinan Transformasional adalah charisma (karisma), individual attention (memperhatikan individu), intellectual stimulation (mendorong staf cerdas), Contingent reward (kesatuan penghargaan) yaitu pimpinan memberikan informasi kepada pengikut tentang apa yang harus dikerjakan agar memperoleh penghargaan, menerapkan dedication (mempunyai kemampuan menyerahkan kehidupannya untuk didarmabaktikan kepada Organisasi demi kemajuan organisasi [5].

Undang-Undang No 14 Tahun 2005 menjelaskan bahwa guru adalah pendidik profesional dengan tugas utama mendidik, mengajar, membimbing, mengarahkan, melatih, menilai, mengevaluasi peserta didik pada pendidikan anak usia dini, jalur pendidikan formal, pendidikan dasar, pendidikan menengah.

Kompetensi guru adalah pengetahuan, keterampilan, kemampuan, atau karakteristik kepribadian seseorang yang mempengaruhi kinerja seseorang secara langsung [6].

Dimensi dari kompetensi pedagogik terdiri dari Guru memahami landasan kependidikan yang diampu, Guru paham terhadap peserta didik, Guru mengembangkan kurikulum, Guru merancang pembelajaran, Guru melaksanakan pembelajaran yang mendidik, dialogis, Guru memanfaatkan teknologi pembelajaran, Guru melaksanakan evaluasi belajar, Guru mengembangkan potensi mahasiswa menjadi efektif [7].

Motivasi adalah forces within a person that effects his or her direction, intensity, and persistence of voluntary behavior [8]. Artinya motivasi adalah kekuatan yang ada dalam diri seseorang yang mempengaruhi arahnya, kehebatannya, ketekunannya untuk berperilaku secara sukarela [8]. Motivasi meruapakan sesuatu kekuatan yang mendorong seseorang untuk bertindak secara sukarela [9]. Motivasi itu merupakan seperangkat faktor dorongan yang menguatkan (energize), menggerakkan (direct), dan memelihara (sustain) perilaku atau usaha seorang Guru [9]. Dimensi dari motivasi ada 3 yaitu: Kebutuhan -kebutuhan berprestasi (need of achievement), kebutuhan bersahabat dengan orang lain (need of affiliation) dan kebutuhan berkuasa (need of power) [10].

Kinerja guru itu hasil kerja seorang guru berupa kemajuan yang telah dicapai dalam bidang tugas mendidik dan mengajar. Kinerja guru menurut Stoner menekankan adanya kemajuan yang dicapai seorang guru pada waktu melaksanakan tugas mendidik dan 
mengajar [11]. Kinerja guru adalah "hasil pekerjaan dalam bentuk jumlah dan kualitas pada waktu tertentu sesuai dengan yang ditetapkan oleh sekolah" [12]. Kinerja guru berkaitan dengan jumlah hasil pekerjaan, dan kualitas hasil pekerjaan guru pada suatu waktu dimana pekerjaan itu harus sesuai dengan persyaratan yang ditetapkan oleh sekolah [13]. Kinerja guru memiliki dimensi terdiri dari kinerja pendidikan, kinerja pembelajaran, kinerja pengembangan keprofesian, kinerja penunjang tugas guru [13].

\section{Hipotesis Penelitian.}

Memperhatikan rumusan masalah, peneliti mengemukpakan hipotesis:

H1 Kepemimpinan Transformasional mempengaruhi Kinerja Guru PAUD di Kecamatan Bungbulang;

H2 Kompetensi Pedagogik mempengaruhi Kinerja Guru PAUD di Kecamatan Bungbulang;

H3 Motivasi Kerja mempengaruhi Kinerja Guru PAUD di Kecamatan Bungbulang;

H4 Secara simultan Kepemimpinan Transformasional, Kompetensi Pedagogik dan Motivasi Kerja mempengaruhi Kinerja Guru PAUD di Kecamatan Bungbulang;

\section{METODE}

Metode penelitian kuantitatif yang dilaksanakan pada penelitian jika dilihat dari tingkat ekplanasinya disebut sebagai metode deskriptif dan metode verifikatif. Teknik pengumpulan data yang dipergunakan oleh penulis adalah kuesioner, wawancara, observasi, studi kepustakaan dan dokumentasi, Unit analisis pada penelitian ini adalah orang yaitu 261 orang guru PAUD di Kecamatan Bungbulang. sebaran Sampel dari 96 Desa di Kecamatan Bungbulang, diperloeh sampel penelitian sebesar 75 responden. Secara proposional sebaran sampel dari 96 Desa, rata-rata masing-masing Desa sebanyak 1-2 responden. Dengan sampel 75 responden diharapkan dapat mewakili (representatif) dari jumlah populasi sebanayk 90 responden. Penelitian ini menggunakan teknik pengambilan sampel berupa clustered stratified proportionate random sampling yaitu penentuan jumlah sampel ditetapkan berdasarkan proporsi (persentase) jumlah suatu golongan dibandingkan dengan jumlah populasi.

Tahapan rancangan analisis terdiri dari uji kualitas instrumen, uji asumsi klasik, uji deskripsi, uji korelasi, persamaan regresi berganda, koefisien determinasi, uji hipotesis [14]. Sebelum menganalisis data kuantitatif berupa data ordinal, maka peneliti menggunakan MSI (Method of Successive Interval), untuk menstransformasikan data yang diperoleh dari skala ukur ordinal menjadi interval

Analisis regresi linier berganda digunakan untuk mengetahui pengaruh dua atau lebih variabel independen dengan satu variabel dependen. Persamaan regresi berganda [14] adalah:

$Y=a+b 1 X 1+b 2 X 2+b 3 X 3+\varepsilon$

(1)

Keterangan:

$\mathrm{Y}=$ Variabel dependen ( Kinerja Guru ) 
$\mathrm{a}=$ Konstanta

b1 = Koefisien regresi variabel

Kepemimpinan Transformasional

$\mathrm{X} 1=$ Variabel independen 1 (Kepemimpinan

Transformasional )

b2 = Koefisien regresi variabel Kompetensi

Pedagogik

$\mathrm{X} 2=$ Variabel independen 2 (Kompetensi

Pedagogik)

b3 = Koefisien regresi variabel Motivasi

X3 $=$ Variabel independen 3 (Motivasi )

$\epsilon=$ Residu atau Faktor-faktor lain diluar X

Untuk menguji hipotesis itu adalah uji t, uji F dan uji signifikansi..Kegunaan uji hipotesis adalah untuk membuktikan bahwa hipotesis yang diduga adalah benar atau sebaliknya.

Dengan derajat ketelitian $(\alpha)=0,05$. Mengetahui nilai $\mathrm{t}$ tabel dilakukan dengan melihat nilai $\mathrm{t}$ pada $\mathrm{t}$ tabel untuk jumlah responden sebanyak n-k-1.

Rumus hipotesis untuk pengujian $t$ pada penelitian ini adalah :

Ho1: $\beta 1=0 \quad$ Kepemimpinan

Transformasional tidak berpengaruh positif dan signifikan terhadap kinerja guru

Ha1: $\beta 1 \neq 0 \quad$ Kepemimpinan

Transformasional berpengaruh positif dan signifikan terhadap kinerja guru.
Ho2: $\beta 2=0 \quad$ Kompetensi Pedagogik tidak berpengaruh positif dan signifikan terhadap kinerja guru

Ha2: $\beta 2 \neq 0 \quad$ Kompetensi Pedagogik berpengaruh positif dan signifikan terhadap kinerja guru

Ho3: $\beta 3=0 \quad$ Motivasi tidak berpengaruh positif dan signifikan terhadap kinerja guru Ha3: $\beta 3 \neq 0 \quad$ Motivasi berpengaruh positif dan signifikan terhadap kinerja guru

Untuk mengetahui seberapa besar pengaruh secara simultan Kepemimpinan Transformasional, Kompetensi Pedagogik, Motivasi terhadap Kinerja Guru ada alat uji yang digunakan dalam penelitian ini yaitu uji $\mathrm{F}$ (Fisher) dengan derajat ketelitian $(\alpha)=0,05$. Cara melihat nilai $\mathrm{F}$ pada tabel $\mathrm{F}$ dilakukan dengan melihat nilai $\mathrm{F}$ pada tabel $\mathrm{F}$ untuk jumlah responden sebanyak n-k

Rumus Uji Hipotesis secara simultan sebagai berikut:

Ho1: $\quad \beta 1, \beta 2, \beta 3=0$ : Tidak terdapat pengaruh secara simultan Kepemimpinan Transformasional. Kompetensi Pedagogik, Motivasi Terhadap Kinerja Guru secara simultan

Ha1: $\quad \beta \mathrm{i}, \beta 2, \beta 3 \neq 0 \quad$ : Terdapat pengaruh secara simultan Kepemimpinan Transformasional. Kompetensi Pedagogik, Motivasi Terhadap Kinerja Guru secara simultan 


\section{HASIL PENELITIAN DAN PEMBAHASAN}

\section{Hasil Analisis Deskriptif}

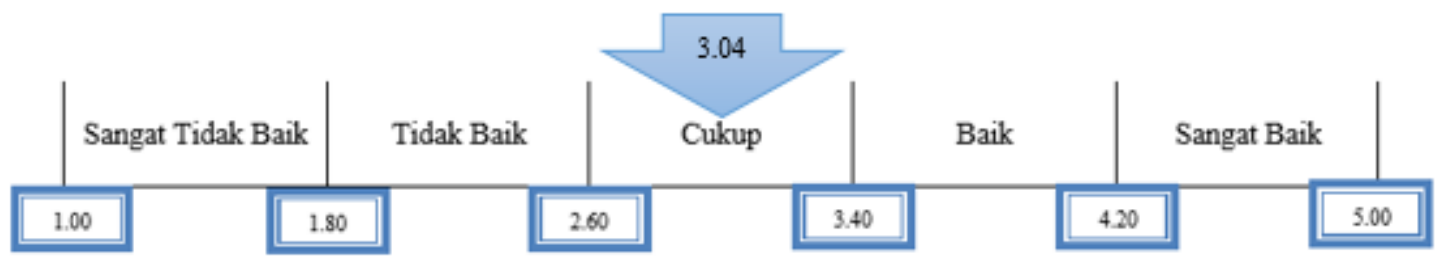

Gambar 1 : Garis Kontinum Kepemimpinan Transformasional

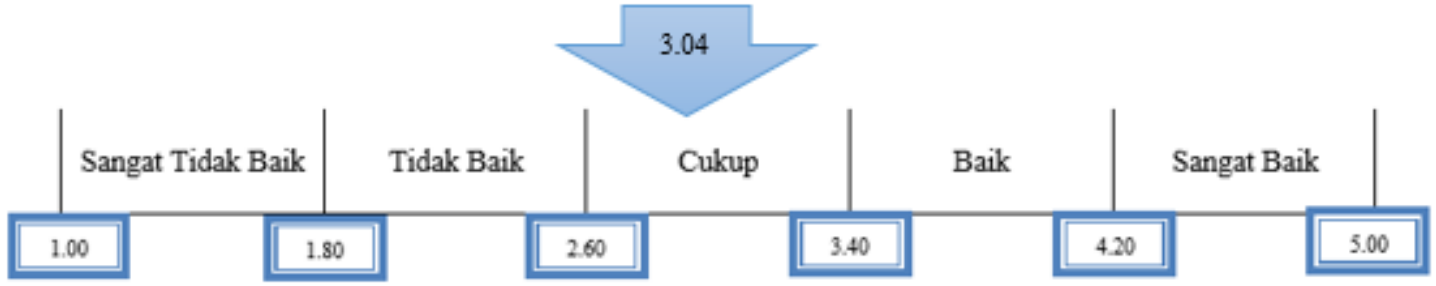

Gambar 2: Garis Kontinum Kompetensi Pedagogik

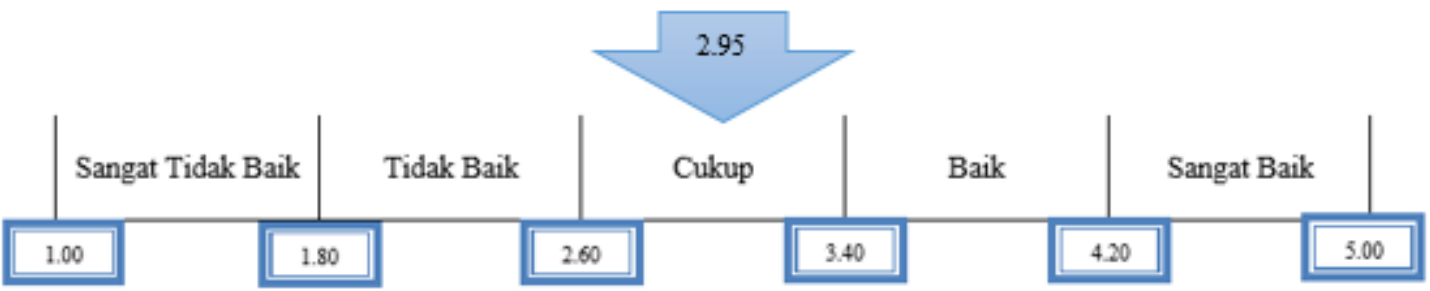

Gambar 3 : Garis Kontinum Motivasi Kerja

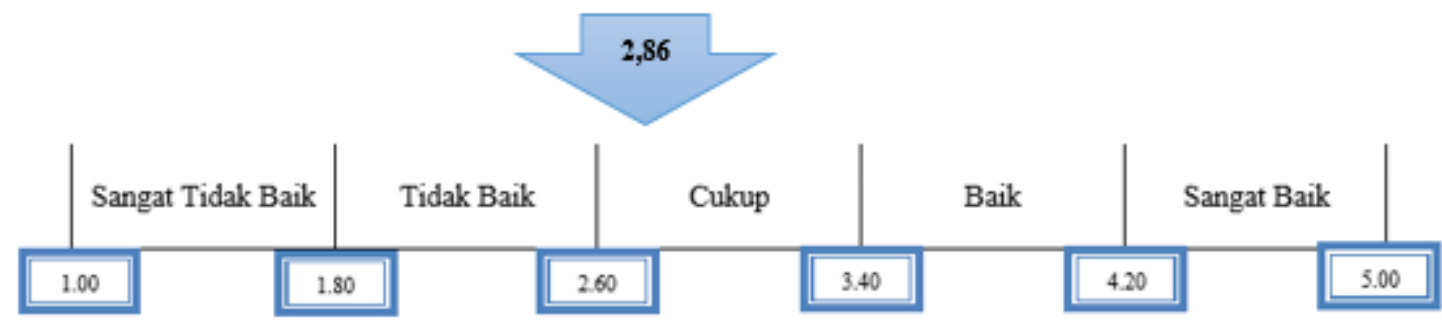

Gambar 4 : Garis Kontinum Kinerja

Hasil Uji Validitas dan Reliabilitas

Pertanyaan pada indikator P1 - P14 tersebut berada di atas angka 0.3 maka pertanyaan- pertanyaan tersebut diputuskan signifikan dan memiliki validitas yang baik.

Tabel 1: Uji Reliabilitas Variabel Kepemimpinan Transformasional $\left(\mathbf{X}_{1}\right)$

\begin{tabular}{|c|c|c|}
\hline Variabel & Nilai Cronbach Alpha & Keputusan \\
\hline $\begin{array}{c}\text { Kepemimpinan } \\
\text { Transformasional }\left(\mathbf{X}_{1}\right)\end{array}$ & 0.906 & Reliabel \\
\hline
\end{tabular}

Pertanyaan pada indikator P15 - P29 tersebut berada di atas angka 0.3 maka pertanyaan- pertanyaan tersebut diputuskan signifikan dan memiliki validitas yang baik. 
Tabel 2: Uji Reliabilitas Variabel Kompetensi Pedagogik $\left(\mathbf{X}_{2}\right)$

\begin{tabular}{|c|c|c|}
\hline Variabel & Nilai Cronbach Alpha & Keputusan \\
\hline Kompetensi Pedagogik $\left(\mathbf{X}_{2}\right)$ & 0.845 & Reliabel \\
\hline
\end{tabular}

Pertanyaan pada indikator P30 - P41 tersebut pertanyaan tersebut diputuskan signifikan dan berada di atas angka 0.3 maka pertanyaanmemiliki validitas yang baik.

Tabel 3: Uji Reliabilitas Variabel Motivasi Kerja $\left(\mathbf{X}_{3}\right)$

\begin{tabular}{|c|c|c|}
\hline Variabel & $\begin{array}{c}\text { Nilai Cronbach } \\
\text { Alpha }\end{array}$ & Keputusan \\
\hline Motivasi Kerja $\left(\mathbf{X}_{3}\right)$ & 0.788 & Reliabel \\
\hline
\end{tabular}

Pertanyaan pada indikator P42 - P61 tersebut pertanyaan tersebut diputuskan signifikan dan berada di atas angka 0.3 maka pertanyaanmemiliki validitas yang baik.

Tabel 4: Uji Reliabilitas Variabel Kinerja Guru (Y)

\begin{tabular}{|c|c|c|}
\hline Variabel & Nilai Cronbach Alpha & Keputusan \\
\hline Kinerja Guru (Y) & 0.907 & Reliabel \\
\hline
\end{tabular}

\section{Model Persamaan Regresi Berganda}

Tabel 5: Hasil Persamaan Regresi Berganda

\begin{tabular}{|c|c|c|c|c|c|c|c|}
\hline \multicolumn{8}{|c|}{ Coefficients ${ }^{a}$} \\
\hline \multirow{2}{*}{\multicolumn{2}{|c|}{ Model }} & \multicolumn{2}{|c|}{ Unstandardized Coefficients } & \multirow{2}{*}{$\begin{array}{c}\text { Standardized } \\
\text { Coefficients } \\
\text { Beta }\end{array}$} & \multirow[b]{2}{*}{$\mathrm{t}$} & \multirow[b]{2}{*}{ Sig. } & \multirow{2}{*}{$\begin{array}{l}\text { Correlations } \\
\text { Zero-order }\end{array}$} \\
\hline & & B & Std. Error & & & & \\
\hline \multirow[t]{4}{*}{1} & (Constant) & -.107 & .139 & & -.767 & .445 & \\
\hline & $\begin{array}{l}\text { Kepemimpinan } \\
\text { Transformasional }\end{array}$ & .303 & .073 & .360 & 4.138 & .000 & .765 \\
\hline & Kompetensi Guru & .488 & .090 & .468 & 5.410 & .000 & .796 \\
\hline & Motivasi Kerja Guru & .179 & .077 & .165 & 2.326 & .023 & .560 \\
\hline
\end{tabular}

Berdasarkan hasil perhitungan pada tabel analisis regresi, diperoleh persamaan regresi linier berganda sebagai berikut :

$\mathrm{Y}=-0.107+0.303 \mathrm{X} 1+0.488 \mathrm{X} 2+0.179 \mathrm{X} 2$

Dari model persamaan regresi linear berganda, dapat dijelaskan bahwa kinerja guru akan menurun, jika tidak didukung adanya kepemimpian transformasional, kompetensi pedagogik dan motivasi kerja guru. Ketiga variabel independent memiliki arah positif, artinya setiap penambahan dari variabel kepemimpian transformasional, kompetensi pedagogik dan motivasi kerja guru, dapat meningkatkan kinerja guru.

\section{Hasil Uji Hipotesis}

Uji hipotesis secara parsial, untuk kepemimpinan transformasional terhadap kinerja guru, diperoleh t-hitung sebesar 4.138 dan derajat bebas (n-k-1) atau 75-3-1 = 71 diperoleh angka t tabel 1.994, sehingga thitung > t-tabel. Artinya HO ditolak dan Ha diterima, maka terdapat pengaruh signifikan antara Kepemimpinan Transformasional terhadap Kinerja Guru. 
Untuk uji hipotesis kompetensi pedogogik terhadap kinerja guru, diperoleh t-hitung sebesar 5.410 dan derajat bebas (n-k-1) atau 75-3-1 = 71 diperoleh angka $\mathrm{t}$ tabel 1.994, sehingga t-hitung > t-tabel. Artinya H0 ditolak dan Ha diterima, maka terdapat pengaruh signifikan antara Kompetensi Pedagogik terhadap Kinerja Guru. Hasil uji hipotesis motivasi kerja terhadap kinerja guru, dimana diperoleh t-hitung sebesar 2.326 dan derajat bebas (n-k-1) atau 75-3-1 = 71 diperoleh angka $\mathrm{t}$ tabel 1.994, sehingga t-hitung > ttabel. Artinya HO ditolak dan Ha diterima, maka terdapat pengaruh signifikan antara Motivasi Kerja terhadap Kinerja Guru.
Dengan demikian hipotesis yang menyatakan Motivasi Kerja mempengaruhi Kinerja Guru PAUD di Kecamatan Bungbulang dapat diterima, sehingga hipotesis 3 diterima. Sedangkan hasil uji hipotesis secara simultan, diperoleh F-hitung sebesar 67.247dan derajat bebas (n-k-1) atau 75-3-1= 71 diperoleh angka F-tabel sebesar 2.73 sedangkan Fhitung sebesar 67.247, sehingga F-hitung > Ftabel artinya $\mathrm{H} 0$ ditolak dan Ha diterima maka artinya terdapat pengaruh signifikan antara variabel Kepemimpinan Transformasional (X1), Kompetensi Pedagogik (X2) dan Motivasi Kerja (X3) terhadap Kinerja Guru secara simultan, maka hipotesis 4 diterima.

Tabel 6: Hasil Analisis Koefisien Determinasi

\begin{tabular}{|c|c|c|c|c|}
\hline \multicolumn{5}{|c|}{ Model Summary } \\
\hline Model & $\mathrm{R}$ & R Square & $\begin{array}{l}\text { Adjusted R } \\
\text { Square }\end{array}$ & $\begin{array}{l}\text { Std. Error of } \\
\text { the Estimate }\end{array}$ \\
\hline 1 & $.860^{\mathrm{a}}$ & .740 & .729 & .26356 \\
\hline \multicolumn{5}{|c|}{$\begin{array}{l}\text { a. Predictors: (Constant), Motivasi Kerja Guru, Kompetensi } \\
\text { Guru, Kepemimpinan Transformasional }\end{array}$} \\
\hline \multicolumn{5}{|c|}{ b. Dependent Variable: Kinerja Guru } \\
\hline
\end{tabular}

Berdasarkan tabel 6, bahwa nilai koefisien korelasi simultan adalah sebesar 0.860 kemudian koefisien determinasi (R2) diperoleh nilai sebesar 0.740 . Artinya total pengaruh antara variabel Kepemimpinan Transformasional (X1), Kompetensi Pedagogik (X2) dan Motivasi Kerja (X3) terhadap Kinerja Guru sebesar $74.0 \%$ sedangkan sisanya $26.0 \%$ merupakan pengaruh variabel-variabel lain yang tidak dijaadikan model dalam penelitian ini.
1. Pendapat responden :

a. Rata-rata skor dari Kepemimpinan Transformasional 3,04 (cukup baik), nilai terendah 2,36 (cukup baik) dan nilai tertinggi 3,68 (sangat baik);

b. Rata-rata skor Kompetensi Pedagogik 3,04 (cukup baik), nilai terendah 2,41 (baik) dan nilai tertinggi 3,55 (sangat baik);

c. Rata-rata skor Motivasi 2,95 (cukup baik), nilai terendah 2,24 (cukup baik) dan tertinggi 3,45 (sangat baik); 
d. Rata-rata skor Kinerja Guru PAUD

2.86 (cukup baik), nilai terendah 2,49

(cukup baik) dan nilai tertinggi 3,57

(sangat baik).

2. Pengaruh Kepemimpinan

Transformasional terhadap Kinerja Guru PAUD di Kecamatan Bungbulang, signifikan;

3. Pengaruh Kompetensi Pedagogik terhadap Kinerja Guru PAUD di Kecamatan Bungbulang, signifikan;

4. Pengaruh Motiasi Kerja terhadap Kinerja Guru PAUD di Kecamatan Bungbulang, signifikan;

5. Pengaruh secara simultan Kepemimpinan Transformasional, Kompetensi Pedagogik dan Motivasi Kerja terhadap Kinerja Guru PAUD di Kecamatan Bungbulang, signifikan.

Kepemimpinan Transformasional, Kompetensi Pedagogik dan Motivasi Kerja berkorelasi dengan Kinerja Guru, sebesar 0,860, menunjukkan adanya hubungan yang sangat kuat. Sedangan nilai koefisien determinasi sebesar 0,740, artinya variasi pengaruh Kepemimpinan Transformasional, Kompetensi Pedagogik dan Motivasi Kerja berkorelasi dengan Kinerja Guru sebesar $74 \%$, sisanya 26\% Kinerja Guru PAUD dipengaruhi oleh faktor-faktor yang tidak dijadikan model dalam penelitian ini.

\section{DAFTAR PUSTAKA}

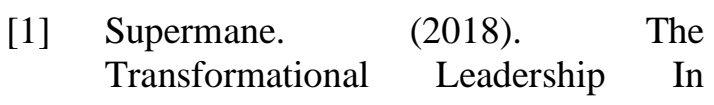

Teacher Education. International Journal Of Academic Research In Business and Social Sciences, Vol 8 No 3, 267-275.

[2] Chick (2015: 5)

[3] Schermerhorn, John R. (2019). Management, 12th ed. New Jersey: John Wiley \& Sons, Inc.

[4] Northouse, P.G. (2019). Leadership: Theory and Practice. California: Sage Publications, Inc.

[5] Gibson. (2019). Organizations Behavior, Structure, Processes. New York: Mc. Graw Hill.

[6] Marwansyah. 2019. Manajemen Sumber Daya Manusia. Edisi Dua. Cetakan keempat. Bandung: Alfabeta,CV [7] Mulyasa, H. E. (2019). Strategi pembelajaran PAUD. Bandung: Remaja Rosdakarya.

[8] McShane, Steven L., Mary ann Von Glinow. 2018. Organizational Behavior. Editon. Emerging Realities for the Workplace Revolution, McGraw-Hill Irwin

[9] Silalahi. (2019). Asas-asas Manajemen. Bandung: Refika Aditama.

[10] Sutrisno. (2019). Manajemen Sumber Daya Manusia. Jakarta: Kencana Prenada Media.

[11] Usman. (2019). Manajemen, Teori, Praktek, Riset. Jakarta: Bumi Aksara.

[12] Aziz. (2019). Manajemen Mutu Perguruan Tinggi. Yogyakarta: Gava Media.

[13] Mulyasa. (2019). Uji Kompetensi dan Penilaian Kinerja Guru. Bandung: Remaja Rosda Karya.

[14] Priyatno. (2019). Belajar Alat Analisis Dan Cara Pengolahannya Dengan SPSS. Yogyakarta: Gava Media. 